\title{
Çivit Otunun Yünlü Kumaşlar İçin Doğal Boyarmadde Kaynağı Olarak Kullanılması
}

\author{
The Use of Woad Plant as A Natural Dye Source for Woolen Fabrics
}

\section{Fazlıhan Yılmaz}

Dr.Öğr.Üyesi, Atatürk Üniversitesi, Güzel Sanatlar Fakültesi, Tekstil ve Moda Tasarımı Bölümü email: fazlihan.yilmaz@atauni.edu.tr (DORCID ID: https://orcid.org/0000-0003-2278-163X

\author{
$\checkmark$ iThentichors \& Aesearcherse" $\mathrm{Bu}$ makale bilimsel etik ve kurallara uygun hazırlanmış ve intihal incelemesinden geçirilmiştir. Etik kurul onayı \\ gerektirmemektedir. \\ Atıf (APA 6)/To cite this article \\ Yılmaz, F. (2020). Çivit otunun yünlü kumaşlar için doğal boyarmadde kaynağı olarak kullanılması. Atatürk Üniversitesi Güzel Sanatlar \\ Enstitüsü Dergisi, 26(45), 485-490. doi: https://doi.org/10.35247/ataunigsed.705347
}

Makale Gönderim Tarihi/Received: 17/03/2020

Makale Kabul Tarihi/Accepted: 06/10/2020

Makale Yayın Tarihi/Published: 22/10/2020

Research Article/Araștırma Makalesi

$\ddot{O} z$

Tüketiciler tekstil mamullerine yönelirken genellikle ilk başta renk ve moda olgusunu ön plana alırlar. $\mathrm{Bu}$ da bir ürünün seçiminde rengin ne kadar önemli olduğunu göstermektedir. Tekstil materyallerinin renklendirilmelerinde eskiden doğal boyalar kullanılırken, bugün yaygın olarak sentetik boyaların kullanıldığı bilinmektedir. Yapılan bu çalışmada ise çivit otu bitkisinin fermantasyon yapılmadan doğal boyarmadde kaynağı olarak yünlü kumaşların renklendirilmesinde kullanılıp kullanılamayacağı test edilmistir. $\mathrm{Bu}$ amaçla farklı bitki konsantrasyonlarında ve farklı mordan maddelerinin varlığında denemeler gerçekleștirilmiş ve elde edilen renkler ve haslıklar incelenmiştir. Nihayetinde çivit otu bitkisinin hiçbir ön işleme tabi tutulmadan direkt olarak kullanımıyla yünlü kumaşları renklendirmede kullanılabileceği tespit edilmiştir.

\begin{abstract}
When consumers tend to textile products, they generally give priority to color and fashion. This shows how important color is in choosing a product. It is known that synthetic dyes are widely used nowadays whereas natural dyes were used in the coloring of textiles in past. In this study, it has been tested whether woad plant can be used as a natural dyestuff without fermentation in the coloration of woolen fabrics. For this purpose, experiments were carried out in different plant concentrations and the presence of different mordant substances and the obtained colors and fastnesses were analyzed. It has been determined that woad plant can be used in coloring of woolen fabrics directly without applying any previous process.
\end{abstract}

Keywords: Color, Natural Dye, Woad, Wool, Fastness

Anahtar kelimeler: Renk, Doğal Boya, Çivit Otu, Yün, Haslık

\section{Giriş}

Renk günlük yaşantımızda önemli rol oynamaktadır (Schueren ve Clerek, 2012) ve boya ile beraber insanlığın estetik arayışları ile ilişkilendirilebilmektedir (Genç, 2014). Renklere olan ilgi doğal bir içgüdüdür ve her birey renklerle ilgili kendi beğeni ve tercihine sahiptir (Bhatti, Adell ve Abbas, 2011). 1856 yılında kimyasal boyaların elde edilmesine kadar renklendirme amacıyla çeşitli bitki, böcek ve deniz kabukluları kullanılmıştır (Genç, 2014).

Doğal boyarmaddelerin büyük bir kısmı bitkisel kaynaklardan elde edilmektedir (Purwar, 2016). Doğada kendiliğinden yetişen veya kültürü yapılan bitkilerin çiçek, yaprak, gövde, gövde kabuğu, ince dalları, toprak altı sürgünleri, yumru kabuğu, kökü, tohumu, çekirdeği veya tamamından farklı yöntemlerle hazırlanan ekstraktlarla yün, pamuk ve ipek gibi hammaddelerin değişik tekniklerle boyanması işlemine "bitkisel boyacılık" denilmektedir (Kayabaşı ve Dellal, 2006). Fakat zaman içerisinde kimyasal boyaların tekstil endüstrisinde kullanım alanları genişledikçe, Türk kültüründe köklü bir geleneğe sahip olan ve bir dönem Anadolu'da da babadan oğula geçen doğal boyamacılık neredeyse yok olma noktasına gelmiştir (Etikan, 2011).

Bitkilerden boyarmaddelerin alınması ve boyamacılıkta kullanılması, sentetik boyarmadde kullanımına göre doğaya zarar vermeyen uygulamalardır (Güngörmez, 2015). Aynı zamanda sentetik birçok renklendirici insan sağlığı açısından zararlı ve alerjenik etkiye sahip olabilmektedir (Angelini, Pistelli, Belloni, Bertoli ve Panconesi, 1997). Öte yandan doğal boyarmaddeler düşük toksik etki gösterme, alerjen etki göstermeme gibi birçok avantaja da sahiptirler (Shams-Nateri, Hajipour, Dehnavi ve Ekrami, 2014). Ayrıca doğal boyarmaddeler sentetik boyalara göre daha iyi biyo-çözünürlük sergilemektedir (Deo ve Desai, 1999). Günümüzde doğal boyarmaddeler genellikle Asya ülkelerinde üretilmektedir (Önal, Eser ve Akıncı, 2013). Anadolu'da boya bitkilerinin çok bulunması boyacılık sanatının eski ve köklü olmasına neden olmuştur (Ölmez, 2005). Ülkemizde boyamacılıta kullanılabilecek yaklaşık 150 kadar boya bitkisi mevcuttur (Kızıl ve Kayabaşı, 2005).

Çivit otu, brassicaceae (Cruciferae) familyasının Isatis cinsine mensup (Parlak, 2007) ve 40 ile 90 cm'ye kadar boylanabilen, iki yıllık, parlak sarı renk çiçekli ve otsu bir bitki olarak bilinmektedir. Çivit otunun (Isatis tinctoria L.) anavatanı Kafkasya yamaçlarıdır ve uzak doğudan Himalayalar'a kadar yayılmıştır. Günümüzde Kuzey Afrika ve Avrupa'da kültürü yapılmaktadır. Çivit otunun 30'a yakın türü Türkiye'de doğal olarak yetişmektedir (Karadağ, 
2007). Bu bitki Orta Çağ'dan 20. Yüzyılın başına kadar indigo kaynağı olarak Avrupa'da yetiştirilmiş ve kullanılmıştır (Stoker, Cooke ve Hill, 1999).

$\mathrm{Bu}$ çalışma kapsamında ise günümüzde önemini kaybetmiş olan çivit otunun yünlü kumaşların renklendirilmesinde kullanılabilirliğinin araştırılması amaçlanmıştır.

\section{Yöntem}

\subsection{Materyal}

Çalışmada $160 \mathrm{~g} / \mathrm{m}^{2}$ ağırlığında, boyaya hazır \%100 yünlü kumaş kullanılmıştır. Yünlü kumaşla yapılan çalışmada atıl durumdaki çivit otu bitkisi boyarmadde kaynă̆ 1 olarak seçilmiştir.

Çivit Otu: Çalışma kapsamında kullanılan çivit otu bitkisi Kayseri'de toplanmıştır. Toplanan çivit otu bitkisi (Isatis tinctoria L.) gölgede kurutulduktan sonra kök, gövde, yaprak ve çiçek olmak üzere bir bütün olarak değirmenden geçirilerek ögütülmüştür. Yünlü kumaşın boyanması işleminde bu öğütülmüş olan çivit otunun çiçekleri, yaprakları ve bütün gövde yapısıyla birlikte kökü de kullanılmıştır. Kullanılan çivit otu bitkisi için önceden herhangi bir fermantasyon işlemi yapılmamıştır. Yani bitki direkt boyarmadde kaynağı olarak kullanılmıştır.

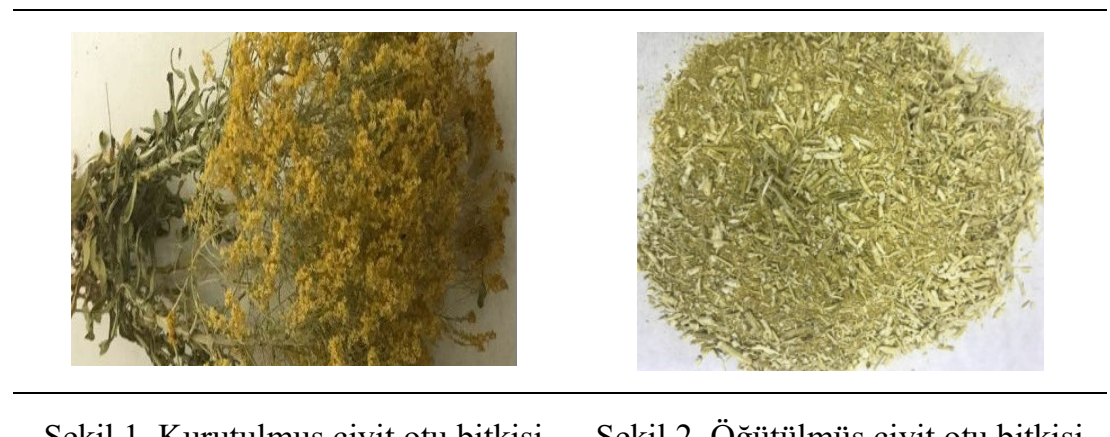

Şekil 1. Kurutulmuş çivit otu bitkisi Şekil 2. Öğütülmüş çivit otu bitkisi

\subsection{Metod}

Boyama denemelerinde kullanılmış olan \%100 yünlü kumaş numuneleri, birlikte mordanlama yöntemine göre çivit otu ile 3 farklı konsantrasyonda boyanmışlardır. Boyama işlemlerinde kullanılan çivit otu herhangi bir ekstraksiyon işlemine tabii tutulmamıştır. Yapılan birlikte mordanlı boyamalarda Şekil 3'deki boyama reçetesine göre boyama banyoları hazırlanmış ve laboratuar tipi numune boyama makinelerinde birlikte mordan yöntemine göre 1/50 flotte oranında boyama işlemleri gerçekleştirilmiştir.

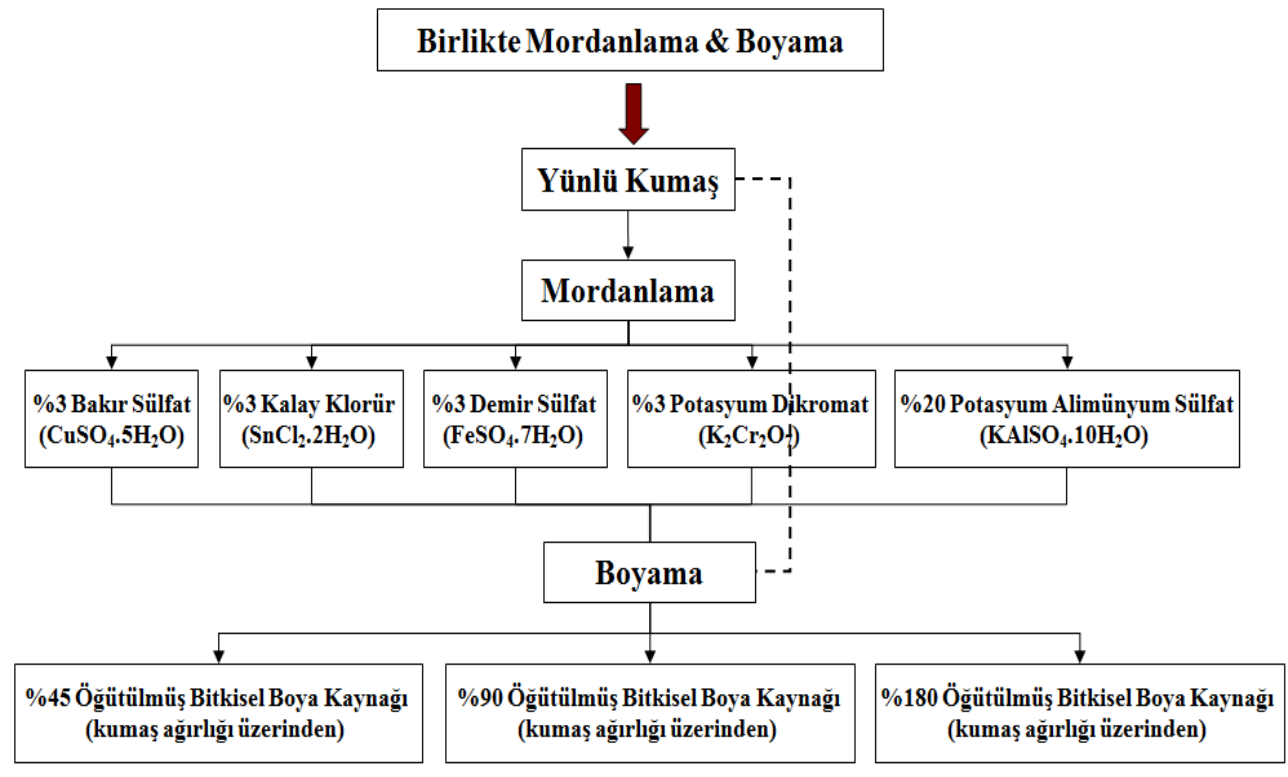

Şekil 3. Birlikte mordanlama ve boyama yöntemine ait reçete 
Daha önceki yapılan çalışmada olduğu gibi (Yılmaz ve Bahtiyari, 2017), doğal boyarmadde, kumaş ve mordan maddeleri boyama banyosunun içine hep birlikte eklendikten sonra boyamaya başlanmıştır. Kumaş boya banyosunda 10 dakika $40{ }^{\circ} \mathrm{C}$ 'de işleme tabi tutulmuş ve daha sonra banyo 40 dakikada $100{ }^{\circ} \mathrm{C}$ 'ye kadar 1 sitılmıştır. $\mathrm{Bu}$ adımlar sonucunda 60 dakikada $100{ }^{\circ} \mathrm{C}$ 'de işleme devam edilerek boyama denemeleri gerçekleştirilmiştir. Mordan kullanılarak yapılan boyama denemelerine ek olarak mordan maddesi kullanılmadan da (mordan maddesiz) boyama işlemleri yapılmıştır. Boyama işlemi tamamlandıktan sonra, çivit otu ile farklı konsantrasyonlarda (\%45, \%90, \%180) boyanmış olan yünlü kumaş önce bir soğuk yıkama ve bunu takip eden sıcak yıkama sonrasında durulama adımıyla birlikte oda sıcaklığında kurumaya bırakılmıştır. Böylece kuruyan kumaş numuneleri çeşitli ölçümleri yapılmak üzere hazır hale gelmiştir.

Boyanmış kumaş numunelerinin D65 1şık kaynağı altındaki CIE L*a*b* değerleri ve renk verimlilikleri (K/S) Konica Minolta 3600d marka spektrofotometre kullanılarak hesaplanmıştır. Bununla birlikte elde edilen renkleri daha iyi gözlemleyebilmek için numuneler taratılarak fotoğraflandırılmıştır. Yapılmış olan boyama denemeleri sonunda kumaşların ışık haslığı ISO 105-B02 standardına göre (ISO 105-B02, 1994) ve yıkama haslığı ISO $105-$ C10 standardına göre (ISO 105-C10, 2006) değerlendirilmiştir.

\section{Bulgular ve Yorum}

Çivit otu ile fermantasyon ve ekstraksiyon işlemi yapılmadan tekstil materyallerinin renklendirme özelliklerini analiz etmek için yapılan işlemler sonrasında kumaşlara ait CIE L*a*b*C*ho değerleri, renk verimlilikleri, boyanmış kumaşlara ait 1şık ve yıkama haslıkları ölçülmüştür. Elde edilen sonuçlar aşağıda sunulmuştur.

Tablo 1

Yünlü Kumaşın Çivit Otu Kullanılarak Boyanması Sonucu Elde Edilen Numunelerin CIELAB (L*, a*, b*, C*ve $h^{\circ}$ ) ve K/S Değerleri

\begin{tabular}{|c|c|c|c|c|c|c|c|c|}
\hline \multirow{2}{*}{$\begin{array}{c}\text { Boyama } \\
\text { Konsantrasyonu }\end{array}$} & \multirow{2}{*}{ Mordan tipi } & \multirow{2}{*}{$\mathbf{K} / \mathbf{S}$} & \multicolumn{5}{|c|}{ CIE L*a*b* (D65) } & \multirow{2}{*}{ Renkler } \\
\hline & & & $\mathbf{L}^{*}$ & $a^{*}$ & $\mathbf{b}^{*}$ & $C^{*}$ & $\mathbf{h}^{\mathbf{0}}$ & \\
\hline$\% 45$ & Mordansız & 1,89 & 72,06 & 2,18 & 20,08 & 20,2 & 83,8 & \\
\hline$\% 90$ & Mordansiz & 2,69 & 68,81 & 1,87 & 22,29 & 22,36 & 85,21 & \\
\hline$\% 180$ & Mordansız & 5,04 & 66,96 & 2,55 & 30,25 & 30,36 & 85,18 & \\
\hline \multirow{5}{*}{$\% 45$} & Bakır II Sülfat & 4,86 & 60,7 & 1,4 & 24,61 & 24,65 & 86,75 & \\
\hline & Kalay II Klorür & 4,94 & 77,19 & 0,27 & 38,04 & 38,04 & 89,59 & \\
\hline & Demir II Sülfat & 1,88 & 71,87 & 1,87 & 18,82 & 18,91 & 84,33 & \\
\hline & Potasyum Dikromat & 3,65 & 63,52 & $-0,63$ & 24,96 & 24,97 & 91,45 & \\
\hline & Şap & 2,07 & 77,08 & 0,79 & 29,14 & 29,15 & 88,46 & \\
\hline \multirow{5}{*}{$\% 90$} & Bakır II Sülfat & 4,98 & 61,11 & 0,79 & 25,17 & 25,19 & 88,97 & \\
\hline & Kalay II Klorür & 8,18 & 74,16 & 0,7 & 40,26 & 40,27 & 89,01 & \\
\hline & Demir II Sülfat & 2,8 & 67,59 & 1,45 & 20,15 & 20,2 & 85,87 & \\
\hline & Potasyum Dikromat & 4,05 & 63,87 & 1,42 & 28,76 & 28,79 & 87,17 & \\
\hline & Şap & 3,11 & 73,62 & 1,19 & 32,75 & 32,78 & 87,92 & \\
\hline
\end{tabular}


Tablo 1'in devamı

\begin{tabular}{|c|c|c|c|c|c|c|c|c|}
\hline \multirow{2}{*}{$\begin{array}{c}\text { Boyama } \\
\text { Konsantrasyonu }\end{array}$} & \multirow{2}{*}{ Mordan tipi } & \multirow{2}{*}{$\mathbf{K} / \mathbf{S}$} & \multicolumn{5}{|c|}{ CIE L*a*b* (D65) } & \multirow{2}{*}{ Renkler } \\
\hline & & & $\mathbf{L}^{*}$ & $a^{*}$ & $\mathbf{b}^{*}$ & $\mathrm{C}^{*}$ & $\mathbf{h}^{\mathbf{0}}$ & \\
\hline & Bakır II Sülfat & 6,38 & 59,06 & 1,26 & 26,92 & 26,95 & 87,31 & \\
\hline & Kalay II Klorür & 14,03 & 66,63 & 1,7 & 38,71 & 38,74 & 87,49 & \\
\hline \multirow[t]{3}{*}{$\% 180$} & Demir II Sülfat & 4,26 & 64,58 & 2,32 & 22,87 & 22,99 & 84,21 & \\
\hline & Potasyum Dikromat & 4,61 & 63,65 & 3,43 & 31,72 & 31,9 & 83,83 & \\
\hline & Şap & 5,48 & 67,82 & 2,45 & 34,17 & 34,25 & 85,89 & \\
\hline
\end{tabular}

Daha önce de belirttiğimiz gibi çivit otu ile boyanmış yünlü kumaş numunelerinin renklerini analiz etmek için CIE $L^{*} a * b *$ değerleri ölçülmüştür. " $L$ *" değeri açıklık eksenidir. Bu değer ideal siyahta sıfirdan başlayıp, ideal beyaz için 100'e ulaşır. " $a *$ " kırmızı-yeşil eksenini, " $b$ " sarı-mavi eksenini, " $C$ " doygunluğu ve " $h$ " renk cinsini (h= $0^{\circ}$ Kırmızı, $\mathrm{h}=90^{\circ} \mathrm{Sar}, \mathrm{h}=180^{\circ}$ Yeşil, $\mathrm{h}=270^{\circ}$ Mavi) vermektedir (Duran, 2008).

$\mathrm{K} / \mathrm{S}$ renk verimliliklerini incelediğimizde bütün deneme adımlarında aynı uygulamalar için boyarmadde konsantrasyonu artırıldığında renk verimliliğinin de artığı gözlemlenmiştir. Bu da genelde beklenen bir sonuç olarak karşımıza çıkmaktadır. Renk verimliliği kalay klorür mordan maddesi ile çivit otu kullanılarak \%180 konsantrasyonda yapılan boyamalarda en yüksek değerini yakalamıştır. Bu değer ise 14,03 olarak karşımıza çıkmaktadır. En düşük değere baktığımızda ise 1,88 sonucu karşımıza çıkmaktadır. Elde edilen değer ise çivit otunun \%45 boyama konsantrasyonu için demir sülfat mordan maddesi kullanılarak yapılan boyama değeridir. Genel olarak demir sülfat mordan maddesi kullanılarak çivit otu bitkisi ile yapılan boyama denemelerinde K/S değerleri düşük çıkmaktadır.

Çivit otu bitkisi kullanılarak yapılan yünlü kumaşların renklendirilme işlemlerinde; kahve, sarı, hâki, hardal ve krem rengine ait çeşitli tonlar elde edilmiştir. Farklı mordan maddeleri kullanılarak mordan maddesiz yapılan boyama denemelerine göre farklı tonda renklerin elde edilebileceği görülmüştür. Örneğin; mordan maddesi kullanılmadan \%90 boyama konsantrasyonunda yapılan denemelerde $\mathrm{a}^{*}=1,87, \mathrm{~b}^{*}=22,29$ ve $\mathrm{h}^{\circ}=85,21$ olarak ölçülmüştür ve renk açık sarı-krem olarak algılanmaktadır. Bakır mordan maddesi ile \%90 boyama konsantrasyonunda yapılan denemelere bakıldığında ise $\mathrm{a}^{*}=0,79, \mathrm{~b}^{*}=25,17 \mathrm{ve} \mathrm{h}^{\mathrm{o}}=88,97$ olarak gözlemlenmiştir. Son olarak da kalay klorür mordan maddesi ile yapılmış olan $\% 45$ boyama konsantrasyonundaki işlemlerde $a^{*}=$ $0,27, \mathrm{~b}^{*}=38,04$ ve $\mathrm{h}^{\mathrm{o}}=89,59$ değerleri bulunmuştur. Bulunan değerler sarı eksene çok yakın bir bölgede olduğundan renk sarı olarak görülmektedir.

L* değeri daha öncede belirttiğimiz gibi açıklığı ifade etmektedir ve bu değer 100'e yaklaştığında elde edilen renk daha açık algılanmaktadır. L* değerini baz alarak baktığımızda bu değer en yüksek olarak kalay mordan maddesi kullanılarak \%45 boyama konsantrasyonunda yapılan boyama işleminde 77,19 olarak görülmüştür. Yani en açık renk bu işlemde elde edilmiştir. L*'nin en düşük olduğu değer ise 59,06 olarak \%180 boyama konsantrasyonunda bakır mordan maddesi kullanılarak yapılan boyama işleminde elde edilmiştir. Bu da en koyu rengi ifade etmektedir.

Ayrıca yapılan boyama denemeleri sonunda kumaşların 1şık ve yıkama haslıkları da değerlendirilmiştir.

Tablo 2

Yünlü Kumaşın Çivit Otu Kullanılarak Boyanmış Numunelerinin Işık Haslığı ve Yıkama Haslığı Test Sonuçları

\begin{tabular}{|c|c|c|c|c|c|c|c|c|c|}
\hline \multirow{3}{*}{ Mordan Maddesi } & \multicolumn{9}{|c|}{ Boyama Konsantrasyonu } \\
\hline & \multicolumn{3}{|c|}{$\% 45$} & \multicolumn{3}{|c|}{$\% 90$} & \multicolumn{3}{|c|}{$\% 180$} \\
\hline & Işık Haslığı & Yıke & Iaslığı & Işık Haslığı & Yık: & aslığı & Işık Haslığı & Ylk & aslığ \\
\hline \multirow{2}{*}{ Mordansız } & & $\mathrm{R}$ & 5 & \multirow{2}{*}{$3-4$} & $\mathrm{R}$ & $4 / 5$ & \multirow{2}{*}{4} & $\mathrm{R}$ & 4 \\
\hline & $3-4$ & A & 5 & & A & 5 & & A & 5 \\
\hline \multirow{2}{*}{$\mathrm{CuSO}_{4} .5 \mathrm{H}_{2} \mathrm{O}$} & 4 & $\mathrm{R}$ & 5 & \multirow{2}{*}{4} & $\mathrm{R}$ & $4 / 5$ & \multirow{2}{*}{4} & $\mathrm{R}$ & $4 / 5$ \\
\hline & 4 & A & 5 & & A & 5 & & A & 5 \\
\hline \multirow{2}{*}{$\mathrm{SnCl}_{2} \cdot 2 \mathrm{H}_{2} \mathrm{O}$} & \multirow{2}{*}{4} & $\mathrm{R}$ & 5 & 4 & $\mathrm{R}$ & 5 & \multirow{2}{*}{$4-5$} & $\mathrm{R}$ & $4-5$ \\
\hline & & A & 5 & 4 & A & 5 & & A & 5 \\
\hline \multirow{2}{*}{$\mathrm{FeSO}_{4} \cdot 7 \mathrm{H}_{2} \mathrm{O}$} & \multirow{2}{*}{3} & $\mathrm{R}$ & $4 / 5$ & 3 & $\mathrm{R}$ & $4 / 5$ & \multirow{2}{*}{4} & $\mathrm{R}$ & $4-5$ \\
\hline & & A & 5 & 3 & A & 5 & & A & 5 \\
\hline \multirow{2}{*}{$\mathbf{K}_{2} \mathrm{Cr}_{2} \mathrm{O}_{7}$} & \multirow{2}{*}{4} & $\mathrm{R}$ & 5 & 4 & $\mathrm{R}$ & 5 & \multirow{2}{*}{$4-5$} & $\mathrm{R}$ & 5 \\
\hline & & A & 5 & 4 & A & 5 & & A & 5 \\
\hline
\end{tabular}


Tablo 2'nin devamı

\begin{tabular}{|c|c|c|c|c|c|c|c|c|}
\hline \multirow{3}{*}{ Mordan Maddesi } & \multicolumn{8}{|c|}{ Boyama Konsantrasyonu } \\
\hline & \multicolumn{2}{|c|}{$\% 45$} & & & & \multicolumn{3}{|c|}{$\% 45$} \\
\hline & Işık Haslığı & Yıkama Haslığı & Işık Haslığı & Yika & aslığı & Işık Haslığı & Yika & Islığı \\
\hline \multirow{2}{*}{$\mathrm{KAISO}_{4} \cdot \mathbf{1 0 H}_{2} \mathrm{O}$} & 3 & $\begin{array}{ll}\mathrm{R} & 5\end{array}$ & \multirow{2}{*}{$3-4$} & $\mathrm{R}$ & $4 / 5$ & \multirow{2}{*}{$4-5$} & $\mathrm{R}$ & 4 \\
\hline & 3 & A & & A & 5 & & A & 5 \\
\hline
\end{tabular}

(A: Akma Değeri, R: Renk Değişimi)

Çivit otu bitkisi kullanılarak yapılan yünlü kumaşların renklendirilme işlemlerinde 1şık haslığı değerleri incelendiğinde genellikle boyama konsantrasyonu arttığında 1 şı haslık değerlerinde iyileşmelerin olduğu gözlemlenmiştir. En yüksek 1şık haslığı değeri 4-5 olarak \%180 boyama konsantrasyonunda kalay klorür, potasyum dikromat ve şap mordan maddeleri kullanılarak yapılan boyama işlemlerinde karşımıza çıkmaktadır.

Yıkama haslığı değerlerine bakıldığı zaman renk değişimi ve akma değerleri için oldukça iyi sonuçların elde edildiği görülmüştür. Akma açısından bütün değerler 5 olarak elde edilirken lekeleme açısından ise 4-5 ve 5 değerleri elde edilmiştir. Bu da çivit otu bitkisi ile boyanan yünlü kumaş numunelerinin yıkama haslıklarının iyi olduğunu göstermektedir.

\section{Sonuç ve Öneriler}

Çivit otu günümüzde Orta ve Batı Anadolu'da yabani olarak yetişmektedir (Deveoğlu ve Karadağ, 2011) ve bu bitkinin yapraklarının fermantasyonu ile mavi renkli bir boyarmadde elde edildiği bilinmektedir (Karadağ, 2007). Bu çalışmada ise çivit otu herhangi bir fermantasyon işlemine alınmadan direkt olarak öğütülmüş ve ekstraksiyon işlemi olmaksızın yünlü kumaşların renklendirilmesinde kullanılmıştır. $\mathrm{Bu}$ kapsamda farklı bitki konsantrasyonlarında ve farklı mordan maddelerinin varlığında denemeler gerçekleştirilmiştir. Ardından boyanmış numunelerin spektral ölçümleri gerçekleştirilmiş ve yıkamaya ve ışığa karşı haslıkları analiz edilmiştir. Elde edilen verilerin sonucunda çivit otunun yünlü kumaşların renklendirilme işlemlerinde herhangi bir ekstraksiyon ve fermantasyon işlemi olmadan da kullanılabileceği görülmüştür. Bunun da ötesinde bu çalışma ile eski önemini yitirmiş olan doğal boyamacılığın tekrardan canlandırılması ve kültürümüzde önemli bir yere sahip olan doğal boyamacılığın ileriki nesillere aktarılması da hedeflenmiştir.

\section{Kaynakça}

Angelini, L. G., Pistelli, L., Belloni, P., Bertoli, A., \& Panconesi, S. (1997). Rubia tinctorum a source of natural dyes: agronomic evaluation, quantitative analysis of alizarin and industrial assays. Industrial Crops and Products, 6(3/4), 303-311. doi: http://doi.org/10.1016/s0926-6690(97)00021-6

Bhatti, I. A., Adeel, S., \& Abbas, M. (2011). Effect of radiation on textile dyeing. P. Hauser (Ed.), In Textile dyeing (p. 1-16), doi: http://doi.org/10.5772/19879

Deo, H. T., \& Desai, B. K. (1999). Dyeing of cotton and jute with tea as a natural dye. Coloration Technology, 115(7-8), 224-227. doi: https://doi.org/10.1111/j.1478-4408.1999.tb00360.x

Deveoğlu, O., \& Karadağ, R. (2011). Genel bir bakış: Doğal boyarmaddeler. Marmara Üniversitesi Fen Bilimleri Dergisi, 23(1), 21-32. Erişim adresi: https://dergipark.org.tr/tr/download/article-file/165552

Duran, K. (2008). Tekstilde renk ölçümü ve reçete çıkarma. İzmir: Ege Üniversitesi Tekstil ve Konfeksiyon Araştırma-Uygulama Merkezi.

Etikan, S. (2011). Doğal boya geleneğinin Türk halı sanatında yeri ve önemi üzerine bir değerlendirme. Türk Sanatları Araştırmaları Dergisi, 1(1), 11-16. Erişim adresi: https://docplayer.biz.tr/39052819-Dogal-boyageleneginin-turk-hali-sanatinda-yeri-ve-onemi-uzerine-bir-degerlendirme.html

Genç, M. (2014). Başbakanlık Osmanlı arşiv belgelerinde kökboya ve cehri ile ilgili bazı kayıtlar. Süleyman Demirel Üniversitesi Güzel Sanatlar Fakültesi Sanat Dergisi, 7(13), 174-212. Erişim adresi: https://dergipark.org.tr/en/download/article-file/193454

Güngörmez, H. (2015). Doğal boyalar ve tuz. Iğdır Üniversitesi Fen Bilimleri Enstitüsü Dergisi, 5(1), 57-63. Erişim adresi: https://dergipark.org.tr/tr/download/article-file/412760

ISO 105-B02. (1994). Textiles-tests for color fastness (Part B02: Color fastness to artifical light). International Organization for Standardization, Brussels, Belgium.

ISO 105-C10. (2006). Textiles-tests for color fastness (Part C10: Color fastness to washing with soap or soap and soda, Test Condition: Test A (1)). International Organization for Standardization, Geneva, Switzerland. 
Karadağ, R., (2007). Doğal boyamacılık. Ankara: T.C. Kültür ve Turizm Bakanlığı Döner Sermaye İşletmesi Merkez Müdürlüğ̈̈.

Kayabaşı, N., \& Dellal, G. (2006). Türkiye'de farklı koyun ırklarından elde edilen yünlerin kökboya ile verdikleri renklerin subjektif ve objektif yöntemlerle değerlendirilmesi üzerine bir araştırma. Süleyman Demirel Üniversitesi Fen Bilimleri Enstitüsü Dergisi, 10(3), 334-340. Erişim adresi: https://dergipark.org.tr/tr/ download/article-file/193647

Kızıl, S., \& Kayabaşı, N. (2005). Muhabbet çiçeğinin (reseda lutea 1.) boyama özelliklerinin belirlenmesi üzerine bir çalışma. Akdeniz Üniversitesi Ziraat Fakültesi Dergisi, 18(2), 195-200. Erişim adresi: https://dergipark.org.tr/tr/download/article-file/18197

Ölmez, F. N. (2005). Yün halı ipliklerinin findık (corylus avellana 1.) yaprakları ile boyanmasından elde edilen renkler ve bazı haslık değerleri. Yüzüncü Yıl Üniversitesi Ziraat Fakültesi Tarım Bilimleri Dergisi, 15(1), 77 84. Erişim adresi: https://dergipark.org.tr/tr/download/article-file/204879

Önal, A., Eser, F., \& Akıncı, İ. (2013). Extraction of dyestuff from basil (ocimum basilium) and investigation of dyeing properties of cotton and wool fabrics using (ure+ammonia+calcium oxalate) mixture. Journal of New Results in Science, 2(2), 19-25. Erişim adresi: https://dergipark.org.tr/tr/download/article-file/105180

Parlak, T. (2007). Çoruh vadisinde bitkisel boya potansiyeli. Ankara: Atatürk Üniversitesi GSF Yayınları.

Purwar, S. (2016). Application of natural dye on synthetic fabrics: A review. International Journal of Home Science, 2(2), 283-287. Erişim adresi: http://www.homesciencejournal.com/archives/2016/vol2issue2/PartE/22-40.pdf

Schueren, L. V. D., \& Clerck, K. D. (2012). Coloration and application of Ph-sensitive dyes on textile materials. Coloration Technology, 128, 82-90. doi: https://doi.org/10.1111/j.1478-4408.2011.00361.x

Shams-Nateri, A., Hajipour, A., Dehnavi, E., \& Ekrami, E. (2014). Colorimetric study on polyamides dyeing with weld and pomegranate peel natural dyes. Clothing and Textiles Research Journal, 32(2), 124-135. doi: https://doi.org/10.1177/0887302X14525658

Stoker, K. G., Cooke, D. T., \& Hill, D. J. (1999). An improved method fort he large-scale processing of woad (isatis tinctoria) for possible commercial production of woad indigo. Agris, 71(4), 315-320. Erişim adresi: https://agris.fao.org/agris-search/search.do?recordID=GB1999001887

Yılmaz, F., \& Bahtiyari, M. İ. (20017). Çeşitli bitkisel kaynaklarla yünlü kumaşların renklendirilmesi. Tekstil ve Mühendis, 24(106), 62-71. doi: https://doi.org/10.7216/1300759920172410602 